\title{
REDESIGNING ARCHITECTURE THROUGH PHOTOGRAPHY
}

\author{
Murat Germen \\ Faculty of Arts and Social Sciences, Visual Arts and Communication Design Program \\ Sabanci University \\ Orhanli, Tuzla, 34956 \\ Istanbul \\ Turkey \\ muratgermen@sabanciuniv.edu \\ http://www.muratgermen.com
}

\begin{abstract}
This paper focuses on the possibility of (re)designing architecture virtually with the help of one of the most important representation tools: Photography. Various digital processes like stitching multiple photos together and mirroring images in image editing software like Photoshop, allow this virtual architecture to take place in virtual environments. Photography can be utilized in the process of 'constructing' a new space -- that we can call 'narrative space'-- from an existing spatial body. This narrative space can also be defined as a 'manufactured metaspace' which is a space beyond reality and representation: A constructed reality that exists solely in digital realms like Second Life.
\end{abstract}

\section{ARCHITECTURE AND REPRESENTATION}

Depending on facilities and technologies available at various periods of the world history, architects used various tools like drawings, paintings, miniatures, models, computers, fine arts platforms to represent their design before and after construction.

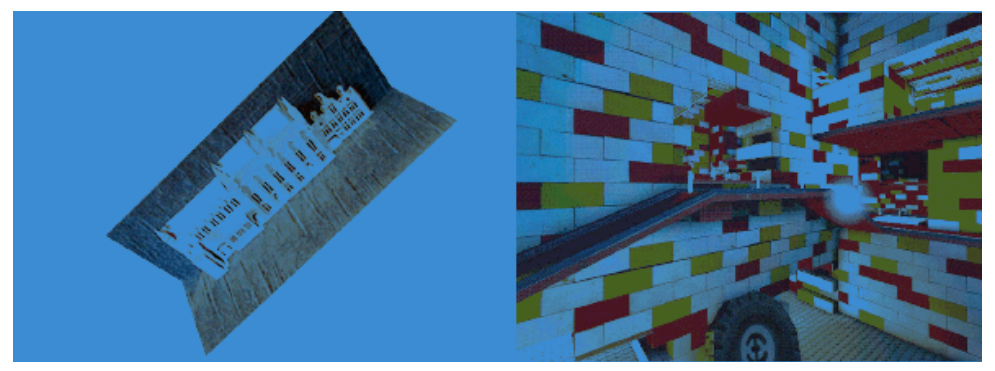

Figures $1 \&$ 2. Left: An “architectural” greeting card. Right: Lego architecture

"Representation includes everything people construct to be known as a visual record or figurative manifestation of that reality. [...] Within this approach, architects usually reduce the definition of representation to the creation of such visual forms as drawings or models that selectively double or imitate the physical reality of a building. I would like to move beyond this traditional view to define representation as a culture-specific and 
dynamic process of establishing the relationships between reality and the signscreated to symbolize this reality. In this process, reality becomes thinkable, and its meanings are symbolically assigned." [1.1]

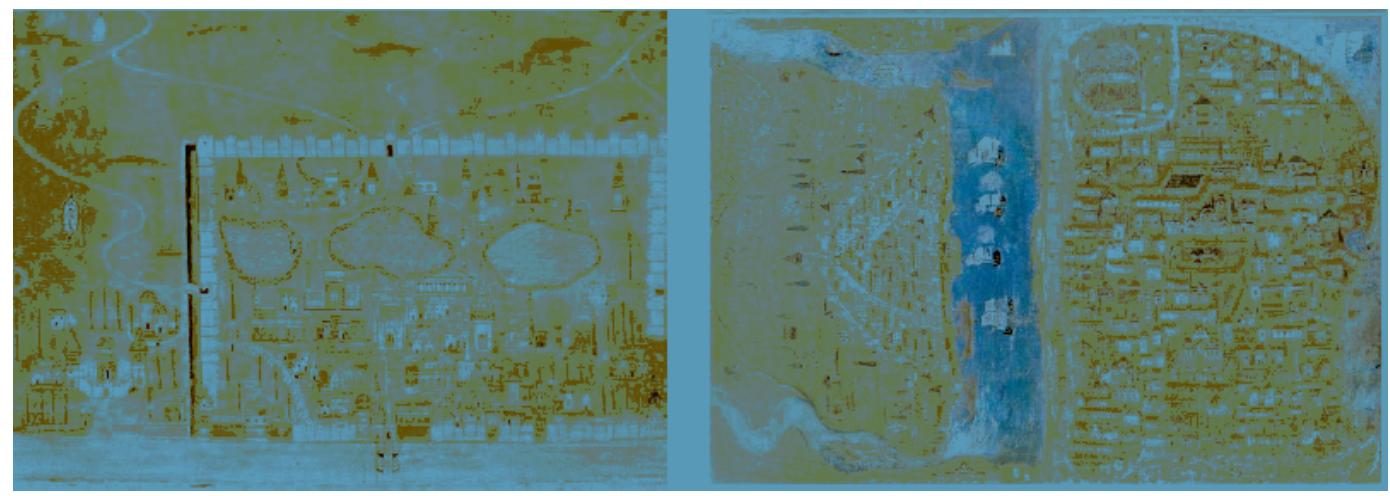

Figures $3 \& 4$. Ottoman miniatures depicting Bagdad (left) and Istanbul (right) by Matrakci Nasuh.

"In general, buildings do not communicate but represent, a distinction essential to the study of architectural specificity of thought. [...] This representational process is far more complex and dynamic than the process of sending, preserving, retrieving, and decoding well-formed messages. [...] Buildings and cities represent when they serve as repositories of materialized concepts that manifest how people have defined themselves in their lived reality. [...] In this way, a building becomes a repository of cultural memory and helps to expand the sense of reality beyond the here and now. Any piece of architecture functions in this manner when its value is found in the interconnections it establishes with other buildings, practices of everyday life, social structures, attributes of the natural environment, or metaphysical concepts, although many aspects of these relationships may be perceivable only to people identifying with the local culture(s). This process of establishing a symbolic network of relationships can be viewed as analogous to what Jean-François Lyotard calls the emergence of representational consciousness. He observes that the viewer's accumulation of experiences and the delay of the immediacy of reaction to what is being perceived at a particular moment show "how perception stops being 'pure', i.e., instantaneous, and how representational consciousness can be born of this reflection (in the optical sense), of this 'echo,' of the influx on the set of other possible - but currently ignored - paths which form memory". Through this process, according to Lyotard, human thoughts establish networks of relationships within functioning concepts of reality. [...]

As the space of representation, a building only foregrounds concepts of reality and implies modes of thought and perception. For example, it invites a tacit dialogue between old and new, or between a culturally shared and a personal sense of reality. Whatever exists or happens in a building, we interact with it symbolically. Any building admits 
various and even conflicting concepts of reality. [...] Such hybridity of meanings is possible because concepts of reality and physical forms of buildings, although symbolically related, are never fully codependent; they are differently constructed. [...] Because buildings do not impose concepts of reality but make them thinkable, many concepts may coexist and be in symbolic dialogue with one another within a physical space. [...] Similarly, it does matter how a person interacting with a building finds personal relevance in this interaction. To reveal these kinds of meanings, the building must somehow engage, like Lacan's mirror, a personal sense of reality." [1.2] This personal sense of reality makes us question the inherent nature of the concept of 'representation' and helps us to extend it into a more flexible (and maybe more correct) notion / formulation of 're-presentation.'

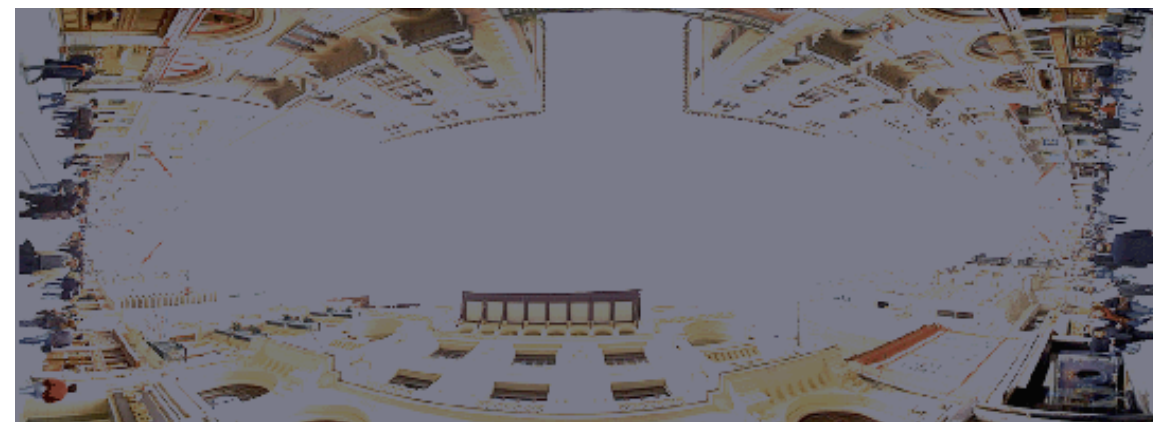

Figure 5. Panoramic photograph of Istiklal Avenue in Istanbul showing both ends of the large pedestrian artery: A personal sense of reality, in other words "re-presentation." Photo by Murat Germen, Istanbul, Turkey.

Movie industry is another platform in which representation has a significant part, especially when it comes to adapting / altering / converting cities for particular needs such as creating futuristic sci-fi cities / architecture that never existed. A particular type of illustration called "matte painting" created by illustrators (and not architects) usually serve as departing points for such architecture. The fact that illustrators can create virtual architecture can also lead to the assumption that photographers who can read space properly can use photography as a tool to re-invent, re-interpret and re-form architecture. The urban space created in Luc Besson's renowned movie "The Fifth Element" is one of the best examples where an "almost impossible" artificial architecture is envisioned and implemented as a simulation. The complicated upwards and sidewards stretch of the built environment takes the limited one-axis 3D volume structure to a richer multiple-axes structure which allow circulation in all directions andnot only horizontal direction as usual. 


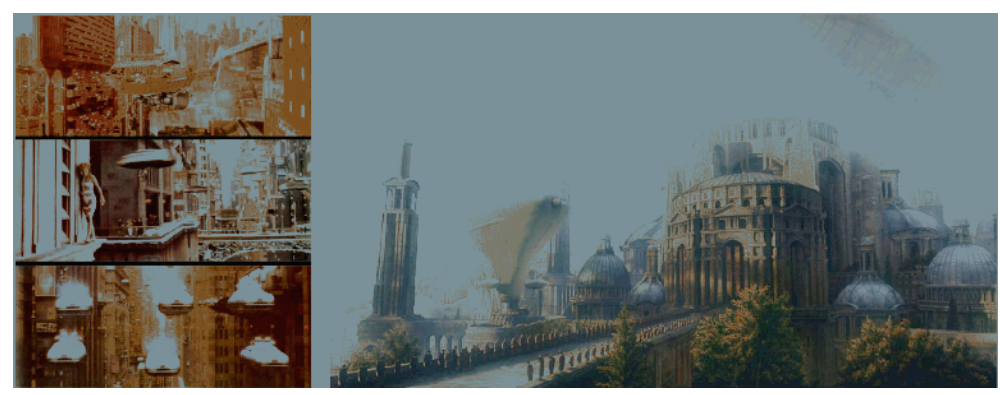

Figures $6 \& 7$. A futuristic city that grows both horizontally and vertically with horizons in all axes. "Fifth Element" by Luc Besson (left). Matte painting by Yanick

Dusseault, depicting a non-existing piece of architecture (right).

It is obvious that fictional processes like movie making and novel writing can be used to expose unseen studies of architecture; by the same token, the most faithful representation tool of architecture, i.e. photography, can also be employed to exercise "fictional" architecture that can later be taken advantage of for "real" architecture to bebuilt.

\section{ARCHITECTURE AND PHOTOGRAPHY}

Photography is the only medium that enables architectural works to be shared with people who do not have access to these works. It is, in this respect, the ultimate representation of architecture that is built. There are various techniques, lenses, rules of thumb that are used in architectural photography in order to make the process as "appropriate" as possible. But these special techniques usually provide us with unique visual recording possibilities that are practically and physically impossible to the naked eye. The so-called "perspective correction" process much used in architectural photography, carries the potential of producing some steeply converging lines, especially when the photographer is close to the building to be photographed. Consequently, the shifting motion in photography causes another shift in our perception: photography does not reflect the truth.

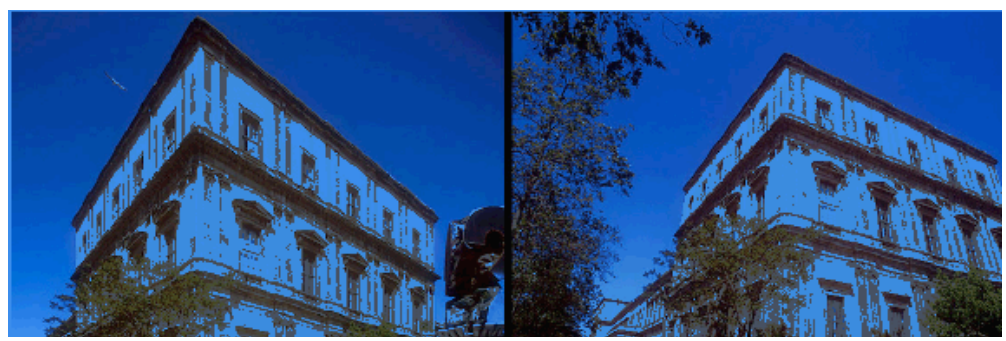

Figure 8. Converging lines due to excessive shifting motion. Photo by Murat Germen. 
Considering the fact that there are different lenses ranging from wide angle to tele, different films for different purposes yielding different contrast histograms, different speed values that lead to various levels of graininess, the fact that we do not see in black and white, etc.; it is possible to assert that cameras do not see in the manner we see and therefore photographs that cameras take have no possibility or reflecting the truth as we see with our eyes. Piotrowski and Robinson approach the problem from another angle: "Photography, on the other hand, filters reality in a different way. A photograph seems to be an 'objective' record of the field of vision that is trustworthy because the photochemical process provides a reliable method of recording an image. [...] All that makes photography appear believable or objective conceals how much a photograph is a constructed representation. Unlike a person's experience in architectural space, a photographer's picture singles out a particular view and freezes it in time. That which the image illustrates is composed to be seen in certain manner, making particular relationships visible and hiding others. Photographers frequently manipulate light, either artificial or natural, to enhance selected attributes of architecture. [1.3] Promotional photographs of architecture [...], rather than supporting a symbolic dialogue between the viewer and a depicted building, encourages the viewer's desire to own a similar kind of architectural commodity. This constructed desire for the represented object shapes the commercial subject-object relationship." [1.4] Following all this, it is quite easy to see that photography is about interpretation and therefore can be used to reinterpret a certain physical existence. In other words, photography can be utilized in the process of 'constructing' a new space --that we can call 'narrative space'-- from an existing spatial body. This narrative space can also be defined as a 'manufactured metaspace' which is a space beyond reality and representation: A constructed reality that exists solely in digital realms like Second Life.

\section{ARCHITECTURE AND CONSTRUCT}

The concept of construction in architectural design process is a temporary process which finally transforms itself into an end "product": A building, a culture, a society, an idea, a freedom, a dogma, etc. Construction sites can be conceived as stages where this process is being "performed" over and over. The inherent incompleteness within the constructing act pushes us to dream; on the other hand, a completed product loses its narrative potential as it informs us on all the necessary pieces that constitute the whole: There is no puzzle to solve or no story to write. Construction sites, in this sense, are like historical ruins; Paul Zucker asserts that "devastated by time or willful destruction, incomplete as they are, ruins represent a combination of man-made forms and of organic nature." [2] As a tribute to and resting on this statement, the more incomplete the "construct" is; the more organic life gets, the more surprises and the less boundaries we have. 


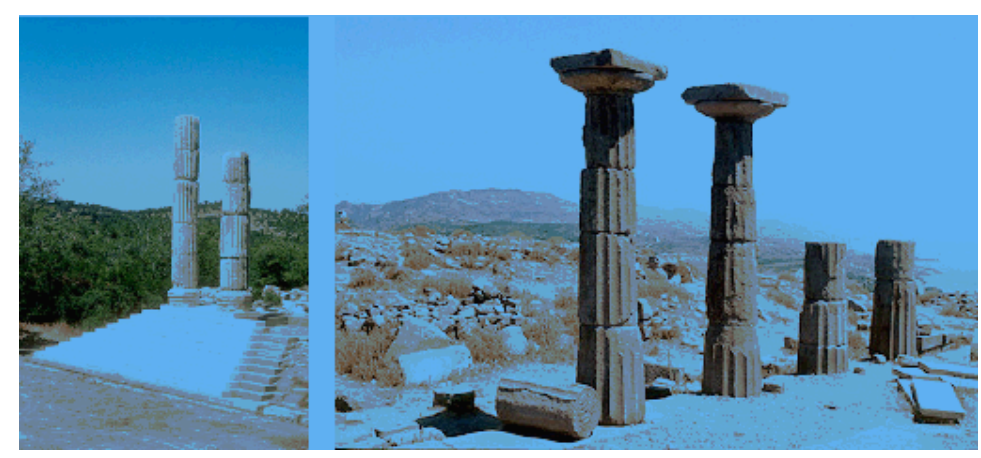

Figures $9 \& 10$. Incomplete ruins that push us to solve the puzzle. Photos by Murat Germen, Assos, Turkey.

Architectural photography has the potential of re-creating the previously mentioned puzzle back again in order to bring an alternative representation to architecture. The architectural photographer is sometimes offered the freedom of reinterpreting, reconstructing architecture in order to be able to present a novel virtual perception to the audience. The idea here is to get some spatial clues that can later be used in other architectural projects. I was personally invited to two different concept exhibits in which I was given the freedom of inventing a virtual architecture through photography. The concept text written for one of these exhibits goes as follows: "I went, saw, stopped, attempted to grasp and enter it, looked at construction process and workers with respect, tried to internalize, wanted to claim it for a while, dreamed of creating a microcosm out of the macrocosm I was in, shot and shot and shot and finally selected: The created world, though intended for all, was probably quite a personal illusion..." 


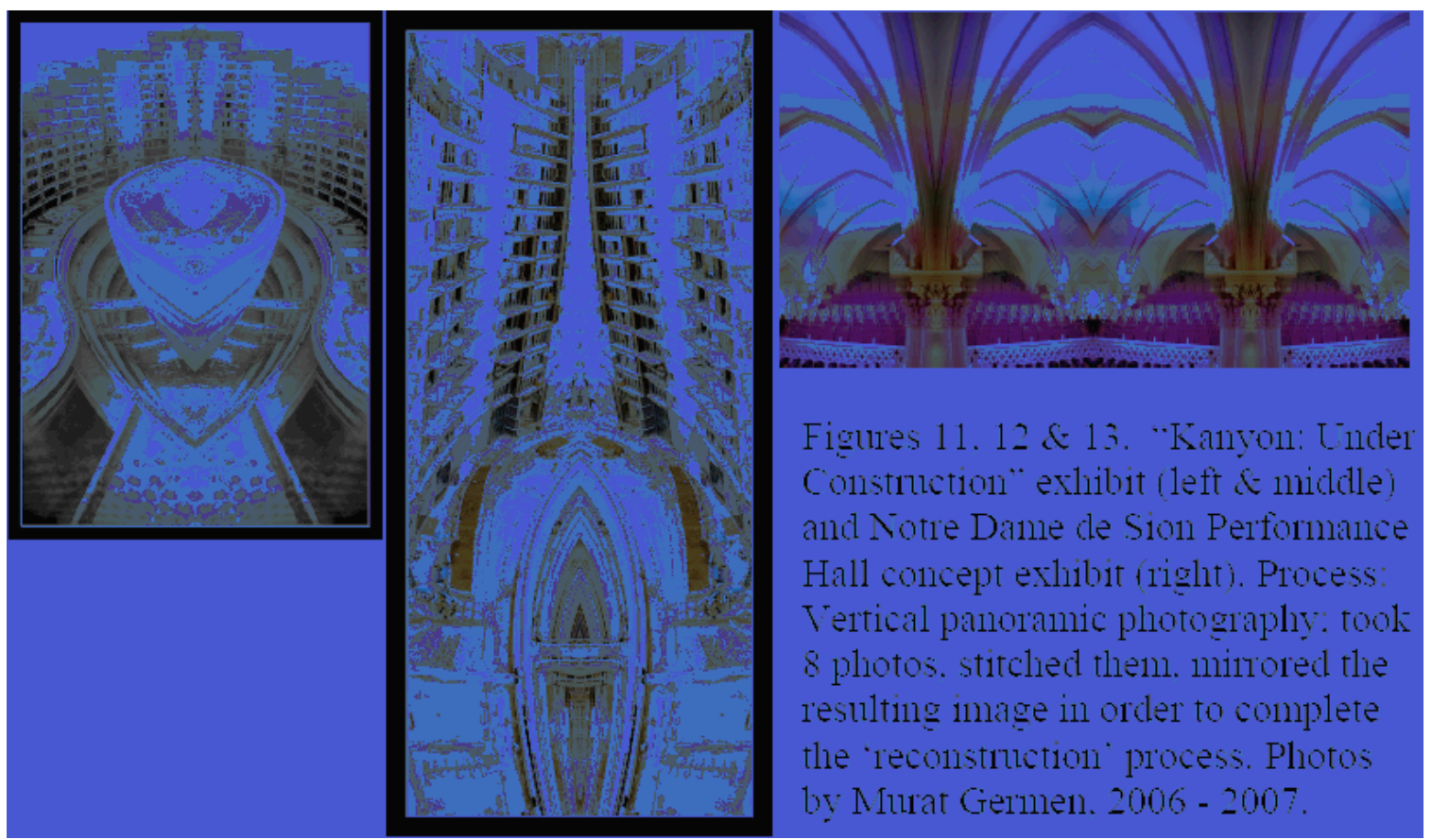

The following quote from William Mitchell will help me in clarifying the notion of "reconstruction of space" better: "The city --as understood by urban theorists from Plato to Aristotle to Lewis Mumford and Jane Jacobs-- can no longer hang together and function as it could in earlier times. It's due to bits; they've done it in. Traditional urban patterns cannot coexist with cyberspace. But long live the new, network-mediated metropolis of the digital electronic era. [3.1] The buildings, neighborhoods, towns, and cities that emerge from the unfolding digital revolution will retain much of what is familiar to us today. But superimposed on the residues and remnants of the past, like the newer neural structures over that old lizard brain of ours, will be a global constructions on highspeed telecommunications links, smart places, and increasingly indispensable software. This latest layer will shift the functions and values of existing urban elements, and radically remade their relationships. The resulting new urban tissues will be characterized by live / work dwellings, twenty-four-hour neighborhoods, loose-knit, far flung configurations of electronically mediated meeting places, flexible, decentralized production, marketing and distribution systems, and electronically summoned and delivered services. This will redefine the intellectual and professional agenda of architects, urban designers, and others who care about the space and places in which we spend our daily lives." [3.2] The above mentioned redefinition process can also be associated with the conception of simulacra as offered by Jean Baudrillard. "During the 1980's, Baudrillard became influenced by Marshall McLuhan and began developing ideas about what determines the nature of social relations, with special emphasis on modes and forms of communication. His most famous formulation about what he calls Simulacra and Simulation fits here. In 'Symbolic Exchange and Death', he argues that the 
Westernsocieties have undergone a 'procession of simulacra', a chain of 'orders of simulacra':

1. The era of the original.

2. The counterfeit.

3. The mechanically produced copy.

4. The simulated "third order simulacra" where the copy has replaced the original.

Baudrillard further argues that in modern society the simulated copy has superseded the original object or the original experience and 'the map has become the territory.' Art theoreticians and philosophers have already discussed the extent to which reality is represented in photographs. The general acceptance today is the idea that photographic images only imply reality or truth and photographs in daily life do replace the reality copied or represented in them. Examples are people kissing loved ones' portraits or the huge industry built around pornography, or mouth watering food photographs." [4] Following this argument, one can justify the motivation of practicing architectural design within the realm of digital photography since the image created within the photograph carries the potential of replacing the "truth." This argument can additionally be supported by the following quote from Lynda H. Schneekloth: "Architecture, landscape architecture, planning, and other environmental design fields are practices whose primary aim is to make the world, to make something new. We give material form to some vision of human society and place. The shadow side of this creation, this making, is that these fields are also about "unmaking" the world. The world already exists, and every time we plan, design, and/or construct some aspect of worldness, we are replacing and therefore unmaking something else." [5]

\section{EXPERIMENTATION IN SECOND LIFE}

Second Life (SL) has recently been quite popular as a customizable virtual environment. Yet, most took it as a game setting and since SL requires more selfmotivation and guidance as compared to online game platforms, they did not exactly find what they were looking for. According to SL experts, this customizable virtual environment is ideal for creative projects to be realized as $3 \mathrm{D}$ volumes, as it allows you to build anything without rules / regulations and has quite an intuitive / advanced 3D modeling environment. This is why I personally wanted to spend some time within SL in order to test what I have been proposing on doing architectural design with photography. Below you will find some screenshots that depict this investigation process. I have used my own photos during the course of action, turned them into 1-bit black \& white images with threshold command in Photoshop, saved them as transparent PNGs, mapped them onto transparent planes within the metaverse and finally built volumes to be "photographed" again by taking screenshots. 
EVA 2008 London Conference 22-24 July Murat Germen
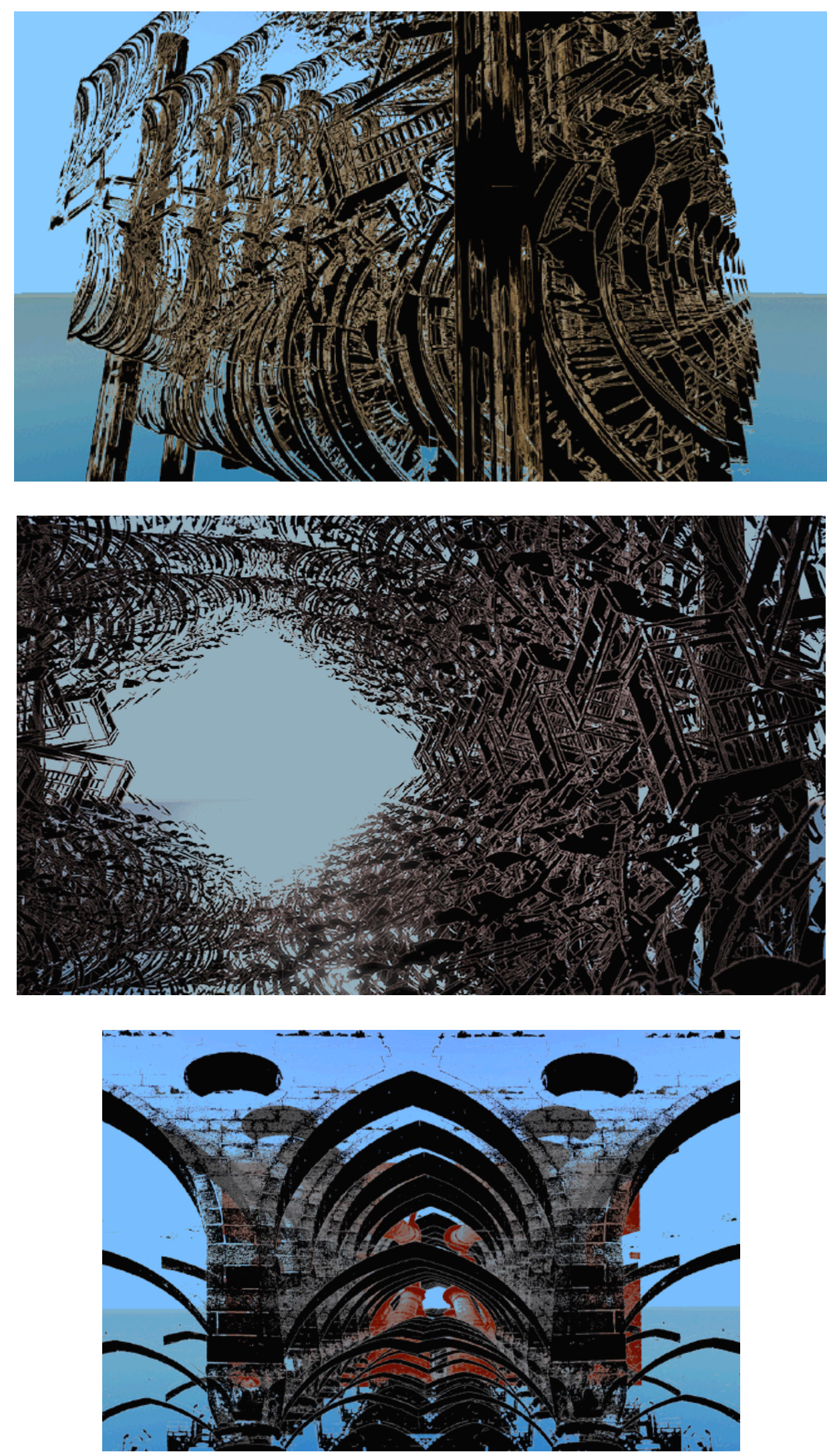
EVA 2008 London Conference 22-24 July Murat Germen
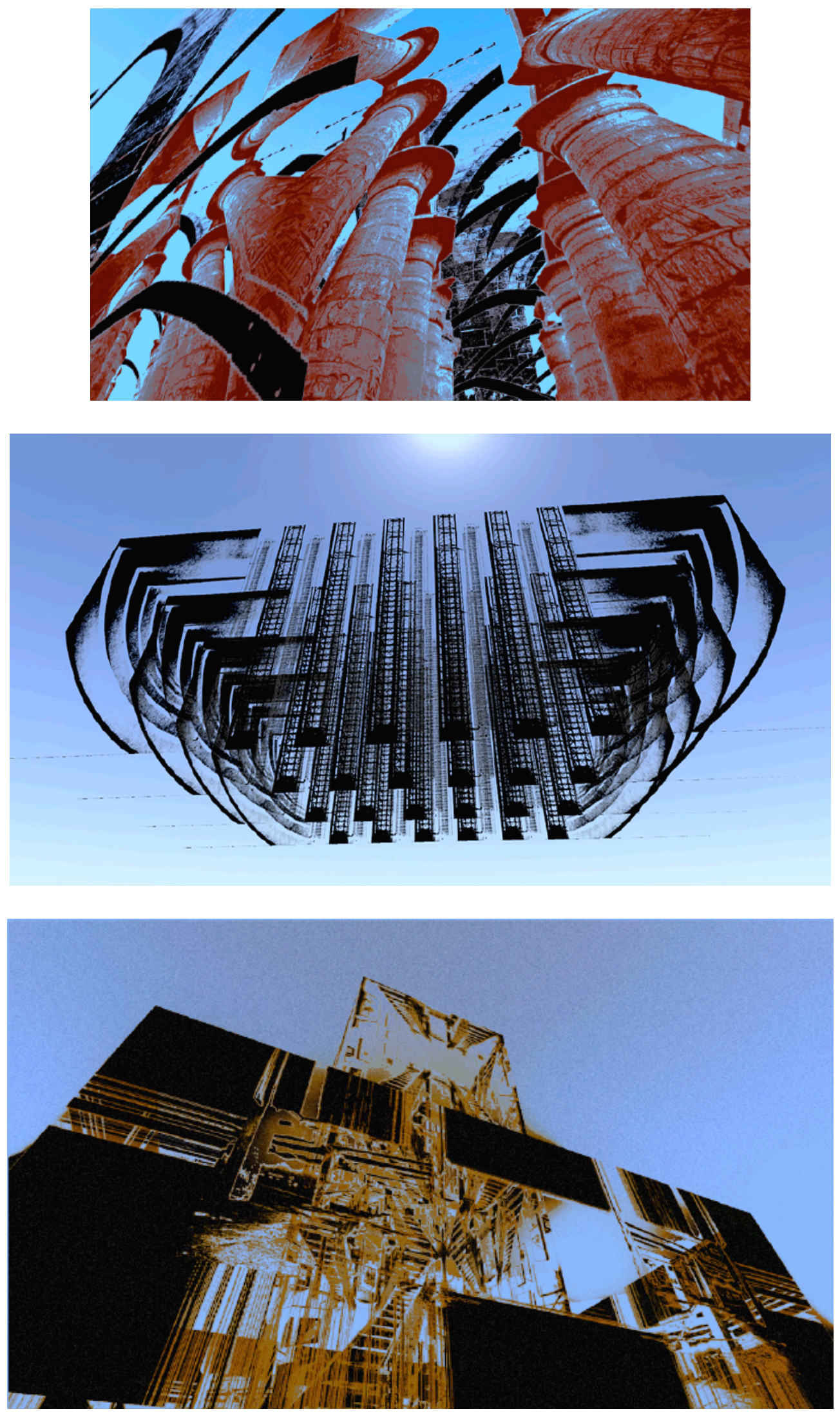

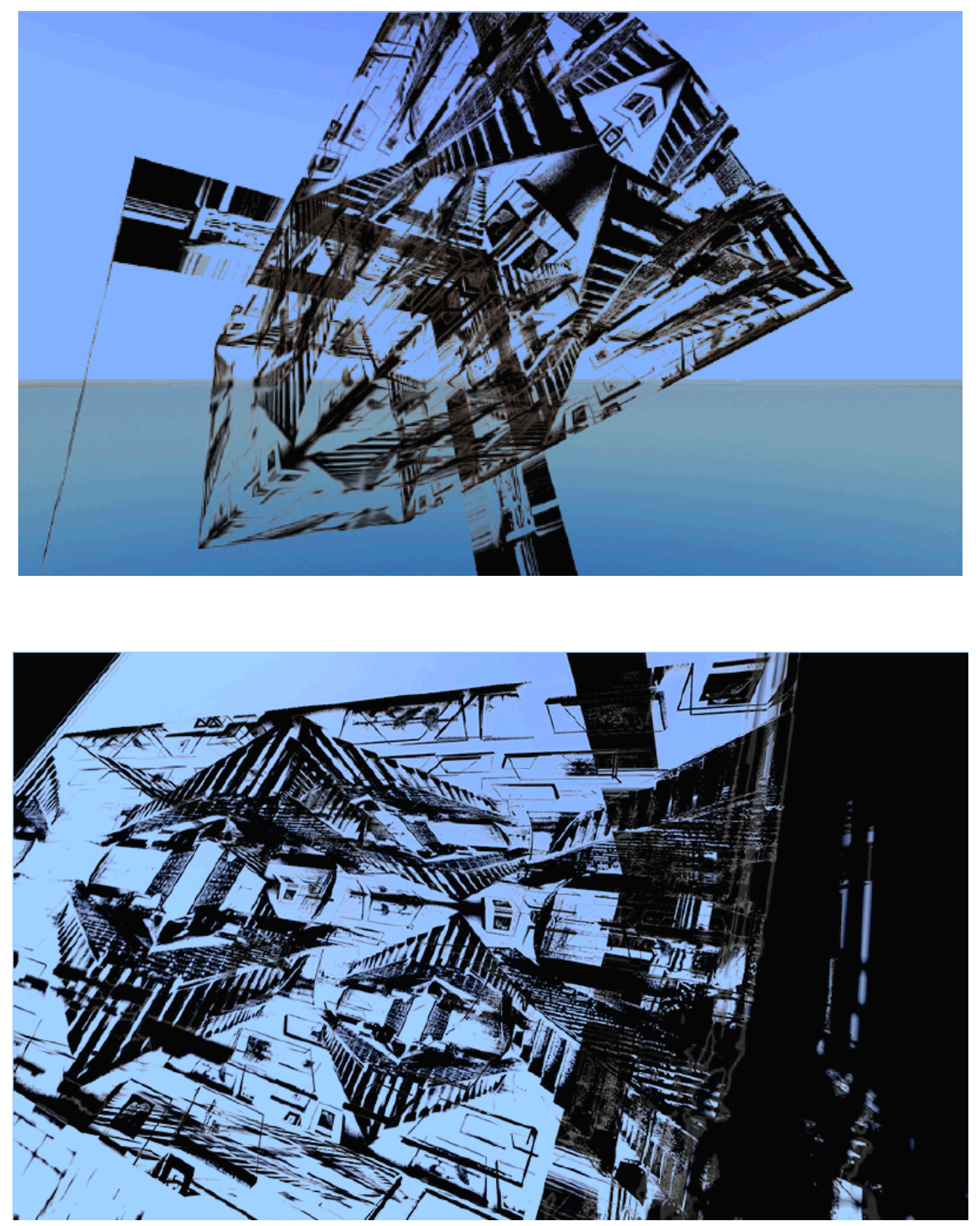

Figures 14, 15, 16, 17, 18, 19, $20 \& 21$ (Above). Architectural experimentation in Second Life using transparent photography mapped on 3D volumes. Photos (20072008) and SL modeling (2008) by Murat Germen.

Figures 22, 23 \& 24 (Below). "Snap" architecture, Murat Germen, "Construct" exhibit, Exhibited at French Cultural Institute, Istanbul, 2007.

\section{CONCLUSION}


Virtual architecture is a term used for architecture specifically created in the computer environment and never used within the realm of architectural photography. This paper concentrates on the prospect of constructing architecture virtually through photography within the metaverse. People like Piranesi, Lebbeus Woods, M.C. Escher, Marcos Novak, etc. previously dreamed about architectures that could exist virtually on paper, screen, digital environments. Space is usually defined / experienced as a physical entity; yet, we recently began to observe that the notion of 'space' can exist / be perceived / used as a non-physical organism by means of interactive media and virtual environment applications in the computer platform. Such creations bring new definitions of "space" and can be named as "informational space" or "cognitive space."

\section{References}

[1] PIOTROWSKI, A. AND Robinson, J.W (eds.): The Discipline of Architecture. 2001, University of Minnesota Press, Minneapolis, pp. 42, 43, 44, 45, 51, 54, 59, 154. <http://www.questia.com>

[2] ZUCKER, P: Ruins: An Aesthetic Hybrid. 1961, The Journal of Aesthetics and Art Criticism, Vol. 20, No. 2, p. 119.

[3] MITCHELL, W.J: E-topia: Urban Life, Jim - But Not as We Know It. 2000, The MIT Press, Cambridge, pp. 3, 7.

[4] CETIN, O.C: Thomas Demand as a Baudrillard Practitioner: The photographic works of Thomas Demand as a Proof of or as Inspired by Jean Baudrillard's Simulation Theory. 2007, VCD508 Term Paper, Bilgi University, Istanbul, Turkey.

[5] SCHNEEKLOTH, L.H: Unredeemably Utopian: Architecture and Making / Unmaking the World. 1998, Architecture, Design and Utopia, Utopian Studies 9.1. <http://www.questia.com> 